\title{
Awareness and Prevalence of Epilepsy; a Study in Educational Hubs at Sheringal, Khyber Pakhtunkhwa, Pakistan
}

\author{
Nazish Akhter ${ }^{1}$, Zul Kamal ${ }^{2,3^{*}}$, Faiz Ur Rahman ${ }^{1}$, Pinky Sultana ${ }^{3}$, Zahra Dhurrani ${ }^{4}$ \\ ${ }^{1}$ Department of Zoology, Shaheed Benazir Bhutto University, Sheringal, Dir Upper, KP, Pakistan \\ ${ }^{2}$ Department of Pharmacy, Shaheed Benazir Bhutto University, Sheringal, Dir Upper, KP, Pakistan \\ ${ }^{3}$ School of Pharmacy, Shanghai Jiao Tong University, Shanghai, China \\ ${ }^{4}$ Hospital Pharmacist, King Edward Medical Hospital and Complex, Lahore, Punjab, Pakistan
}

\begin{abstract}
*Corresponding Author: Zul Kamal, Department of Pharmacy, Shaheed Benazir Bhutto University, Sheringal, Dir Upper, KP, Pakistan, Email: xulkamal@sbbu.edu.pk
\end{abstract}

\begin{abstract}
The main aim of the study was to determine the prevalence and awareness of epilepsy within the educational hubs in Sheringal, Khyber Pukhtunkhwa, Pakistan. The study area were further divided into primary (play group-class $5^{\text {th }}$ students), secondary (school and college students), tertiary (university graduate and post graduate students) and professional (teaching, non-teaching, administrative and class four staff of university, college and school) level. Data was generated through pre-designed structure questionnaire which had a sensitivity of $100 \%$ for identifying persons with epilepsy. The total targeted population were $n=$ 5308; in which $n=114$ (2.15\%) were confirmed epileptic patients. High prevalence rate per thousand of the population were found in professional level (54.5) and (29.4) among primary level. Similarly among age and sex prevalence ratio; $n=86$ and $n=28$ epileptic patients among $n=3256$ male and $n=2052$ female population respectively; which were highly consistent within the age range of 11-20 years (61.4\%). The awareness regarding familiarity and understanding diseases status is also very poor. It is concluded that the prevalence rate of epilepsy in Sheringal is very much higher than those reported in most other communities of Pakistan as well as of developed and underdeveloped countries. Proper educations, trainings, awareness campaigns at all levels can change the negative attitude, false perceptions and stigmatization about epilepsy in remote areas of Pakistan.
\end{abstract}

Keywords: Awareness, education hubs, epilepsy, prevalence, Sheringal.

Abbreviations: AEDs: Anti-epileptic drugs; KP: Khyber Pakhtunkhwa; MRI: Magnetic resonance imaging; CT: Computer topography; PINS: Pakistan international neuroscience society; yrs: Years;

\section{INTRODUCTION}

Epilepsy is one of the major chronic neurological disorders characterized recurrent seizures which are relatively a common condition that may affect anyone, at any unpredictable age and location of the brain. A seizure happens when abnormal electrical activity in the brain causes an involuntary change in body movement or function, sensation, awareness, or behavior. These seizures may vary from a temporary disruption of the senses to short periods of unconsciousness or staring spells and convulsions. The terms Epilepsy and seizure disorder are interchangeably used. Epilepsy is a chronic disorder mostly caused by several conditions hampering an individual's brain such as stroke, alcohol or drug effects, complications during childbirth, infections such as meningitis, encephalitis, cysticercosis or brain abscess and certain genetic or inherited disorders [1, 2].

Epilepsy is basically divided into two types: partial; when electrical activity occurs in a specific area of the brain and generalized involving the seizure of the entire brain. Apparently these kind of seizures may start as "partial" followed by converting itself into a "generalized" one[3]. Furthermore, generalized seizures have subtypes such as absence, atonic, tonic, myoclonic and tonic-clonic. Diagnosis of Epilepsy's based on an accurate description by those who had witnessed the conditions, situations and the frequency. It is confirmed by electroencephalogram but absence of characteristic abnormalities does not exclude a diagnosis of epilepsy if the clinical evidence is 
strong. Accurate diagnosis of the type of seizure is important in determining which medication is most likely to be effective, and for prognosis and lifestyle advice [4].About two thirds of all people with epilepsy will be well-controlled with AEDs and some will go into remission and be able to come off medication. Most people with epilepsy will need some degree of specialist overview of their management but the general practitioner is well placed to play a major role in coordinating both diagnosis and treatment [5].

Among the world population, 50 million people are reported to be affected by epilepsy and approximately $85 \%$ are the ones residing in developing countries. It has been estimated that $10 \%$ of the world's population who live a normal lifespan can expect to have at least one epileptic seizure [6]. Throughout the world, epileptic patients are forced to face social stigma and discrimination; in addition, they are deprived from disclosing their condition or to seek any proper treatment, the reason why epilepsy continues to grow as a stigmatizing disease among the developing countries. Recently conducted knowledge, surveys attitude and practice studies on stigmatization, prevalence, awareness, epidemic and endemic studies from developed countries have shown an emergence of a positive attitude and behavior towards epilepsy treatment and management. As education plays a major role, educated individuals seem to express a positive perception for epilepsy; however, erroneous belief still prevails in innumerable areas with lack of education [7-9].

In countries Such as United States and Denmark, enhanced public knowledge and approach towards epilepsy have reported as a result of strapping public awareness and their willingness to understand the state of an epileptic patient. On the other hand; prevalence studies regarding epilepsy has revealed increasing number of studies from both developing and developed countries [8,9].

Ancient belief and myths regarding this disease still holds a strong base in this modern era. Most of the believers reckon it as a demonic possession and they call it as "peeryan" in local pashto language meaning spirit or phantom. Measuring the rate of prevalence and spreading the awareness has been the primary steps to alleviate discriminations on the patients [10]. The epidemiological and community based studies completely lacks in this region and however this disease roots to be the common kind in such harsh area. Based on these facts, education hubs were designed that included primary, secondary schools, graduates and professional employees. What could be the possible reason for the disease to have such a higher degree of prevalence in these mountainous areas? Is nature playing any role? Is the cause food habits or lifestyle? All these questions need the attention of researchers and especially WHO for extensive research exploration. Neurocysticercosis, birth brain injury, intracranial infections, cerebrovascular disease, food, water, genetic and inherited factors should be investigated in this area for aetiological findings.

Prevalence is the measurement of a disease burden in the community, which has to be considered when planning the health needs at local, regional, and national levels. While knowing the degree of awareness, understanding and attitude toward a disease in a society is a necessary first step in eradicating discrimination against persons carrying the disease[8, 11]. Epidemiologic studies on epilepsy show wide variations in prevalence rates (PRs) from 0.9 to 57 per 1000 population [12]. Studies of the prevalence of epilepsy from the developing world have shown prevalence rates 2 to 25 times higher than the average prevalence rate of 5 to 6 per 1,000 in developed countries. This difference may be featured as misdiagnosis, unreliable definitions of epilepsy, failure to take into account the disease activity and contradictory definition of active epilepsy. While sometimes related to geographically relevant risk factors such as poverty, illiteracy, poor sanitation, inaccessibility of medical care, birth and accident related head trauma, cerebral cysticercosis and hot water induced seizures [8]. The global prevalence of epilepsy is generally taken as between 5 and 10 cases per 1000 persons. A very few epidemiological studies of epilepsy are available from Pakistan. This subject has not been thoroughly investigated especially in remote and hard areas. The recent estimates of population of Pakistan exceed 188.2 million[13]. Whereas the total number of trained neurologists in Pakistan is estimated to be less than 30 (verbal communication at the annual meeting of Pakistan International Neuroscience Society 2001). There are approximately 350 neurologists of Pakistani origin in North America (Data collected by 
PINS from various directories of neurologists 2001). Based on the available data, it is estimated that 1.38 million people are suffering from epilepsy in Pakistan, which makes it one neurologist available for every 46200 sufferers of epilepsy [14].

Nationwide surveys on prevalence, awareness, attitude, knowledge and stigmatization have been conducted in various countries with different cultural, religious and traditional backgrounds for example United States, Denmark, Finland, Japan, Italy, China, Taiwan, Hong Kong and India [8, 10]. However in Pakistan it was never done especially in remote areas. So national wide extensive researches are utmost needs and required. In Pakistan prevalence of epilepsy in general population is estimated to be 9.99 per 1,000 populations. Rural population was accounted to have twice the number (14.8/1000) as compared to urban population (7.4/1000) [15].In population based studies, age and sex demographic distributions show discrepancies it appeared that the ubiquity was dominated by female as compared to male, In addition the degree of occurrence was found to be more in the younger population i.e. $<30$ yrs and supremacy ranging between $20-40$ yrs of age, followed by reduced prevalence between $40-60$ yrs of age. Among the pediatric age group, the pervasiveness of epilepsy is 18.5 $(0.8-49.0)$ per thousand. Thus, children younger than 2 years of age and adults older than 65 are most likely to be affected [14].

Generalized seizures were the most common seizure type in Pakistan. Among this the primary and secondary generalized seizures were reported in $52-70 \%$ and $15-25 \%$ cases respectively. Though the differentiation between primary generalized seizures and secondary generalized seizures was somewhat challenging to monitor. Similarly simple partial and complex partial seizures were reported in 5-9\% and 5$12 \%$ cases respectively [16]; In this era; near about $21-76 \%$ of epilepsy is considered as idiopathic. The supposed etiology varied between different age groups. Khan., et al reported history of perinatal complications in $76 \%$ of their sample [16]. Similarly Afzal .,et al reported $24 \%$ of meningitis or encephalitis cases, $24 \%$ patients had febrile seizures, $1 \%$ had hypoxic ischemic encephalopathy, $11 \%$ mental retardation and chromosomal abnormalities, $21 \%$ were considered idiopathic [17]. Aziz., et al have reported meningitis in $3.3 \%$ of cases; encephalitis in $6.6 \%$ of cases, neonatal jaundice in $7.5 \%$ cases, neonatal convulsions in $14.3 \%$ cases, hypertension in $5.4 \%$ cases and ischemic heart disease in $1.3 \%$ cases. In their study, $61.6 \%$ of cases were considered to have idiopathic epilepsy [18]. There are very few researches about the social responses and social unacceptability of epilepsy. Among the societal responses, epilepsy was taken to be contagious by $6.4 \%$ patients whereas $8.1 \%$ thought that it could lead to other ailments and $20.7 \%$ felt that people with epilepsy should not marry while only $3.1 \%$ endorsed their epilepsy to supernatural causes. Thus, this study was therefore undertaken to determine the prevalence and awareness of epilepsy among the primary, secondary, tertiary and employment level with in the educational hubs in Sheringal.

\section{METHOdOLOGY}

\subsection{General Description of the Area}

Sheringal is one of the beautiful valleys; sited and surrounded by the beautiful Koh-eHindukush mountains; which is located between $350^{\circ}$ to $280^{\circ}$ North latitude and $720^{\circ}$ to $200^{\circ}$ East longitudes of district Dir Upper, located in Khyber Pakhtunkhwa (KP) of Pakistan. Altitude is approximately $2000 \mathrm{~m}$ above the sea level [19]. The total area covered by this hilly valley is 7992.67 hectares, having total population of about 20,000. Farming, horticulture, carpentering, milling, local mercantilism of woods are the socio-economic profession of the peoples of this areas. This area is too much hard and remote with very low literacy rate $(51 \%)$ [20].

\subsection{Study Area}

Shaheed Benazir Bhutto University (SBBU) and Government primary, high and higher secondary schools (both for male and females), which are situated within Sheringal valley; were the study areas. These were the main education hubs providing education at primary, secondary, undergrad and postgraduate level.

The study area was divided into various levels

i. Primary level: includes children's from playgroup to class $5^{\text {th }}$ from university public school (male and female sections), government primary schools (male and female sections).

ii. Secondary level: includes school and college students both from university public high school and college and government 
higher secondary schools (male and female sections).

iii. Tertiary level: includes SBBU graduated and post graduate students from all faculties.

iv. Professional level: While in this level mostly keep teaching, non-teaching and administrative staff of all schools, colleges and university.

All of these makes a total of $n=5308(20,000$ total population of the area) population; among these $n=3256$ were male while $n=2052$ were that of female. Similarly at primary $(n=1800)$, secondary $(n=2145)$, tertiary $(n=959)$ and professional $(n=404)$ level were studied for the desire findings.

\subsection{Study Design}

Conducted across sectional survey from April to September, 2015. Sample size was calculated as $n=5308$, from the target population of 20,000. A stratified random sampling technique was used. Various questioners were designed in such a way that can gives clear determinants about the age-sex prevalence, level of awareness, familiarity and understanding of epilepsy. The screening questionnaire administered had a sensitivity of $100 \%$ for identifying persons with epilepsy. Mostly interviewed those patients that were declared by neurologists as an epileptic patient. The left of the population were designated as non-epileptic population. The awareness and prevalence's were determined in epileptic and non-epileptic patients. These procedures also have been used by other authors $[9,12,21,22]$.

\subsection{Sampling Tools}

A data base was generated through a predesigned structure questionnaire. A total of 24 questionnaires; which were mentioned in Table 3.1 and 3.2. The questionnaire was designed to cover the basic acquired questions regarding epilepsy awareness and prevalence responses. All were closed end questions; with "yes", "no" or "don't know" responses. The questionnaire had been field-tested for the first time in this remote area. For awareness; randomly distribute a total of $n=500$ questionnaires among secondary, tertiary and professional level. Primary levels were excluded from this response; as they were mostly children of playgroups.

\subsection{Data Analyses}

Data were mostly evaluated through descriptive statistics by using Microsoft office Excel 2007 and Graph Pad Prism 5.00. We used simple mean and percentages were ever applicable.

\section{RESUlT}

According to analysis, a total of $n=114$ (2.1\%) positive cases (epileptic) irrespective of educational level. High prevalence percentages were recorded in female at primary $(60.7 \%)$ and secondary (35.7\%) level. However, male population had higher $(20.9 \%$ and $12.8 \%)$ rate of prevalence at tertiary and professional level respectively. Table 1; shows prevalence of epilepsy among different level, while Figure 1; graphically shows epilepsy prevalence per thousand population; which are higher among professional (21.5) as compared to primary level (29.4), secondary level (13.1) and tertiary level (11.6).

Table1: Prevalence of Epilepsy among different level of people within an educational hub at Sheringal $(n=5308)$

\begin{tabular}{|c|c|c|c|c|c|c|}
\hline \multirow[t]{2}{*}{$\begin{array}{l}\text { Population } \\
\text { Sampled }\end{array}$} & \multicolumn{2}{|c|}{ Sampled Population } & \multicolumn{2}{|c|}{$\begin{array}{l}\text { Epileptic Population } n \\
(\%)\end{array}$} & \multirow[t]{2}{*}{ Total Affected } & \multirow[t]{2}{*}{$\begin{array}{l}\text { Per thousand } \\
\text { Population }\end{array}$} \\
\hline & $* \mathbf{M}$ & $* * \mathbf{F}$ & $\mathbf{M}$ & $\mathbf{F}$ & & \\
\hline${ }^{\mathrm{a}}$ Primary Level & 970 & 830 & $36(41.9)$ & $17(60.7)$ & 53 & 29.4 \\
\hline${ }^{\mathrm{b}}$ Secondary Level & 1008 & 1137 & $18(20.9)$ & $10(35.7)$ & 28 & 13.1 \\
\hline${ }^{\mathrm{c}}$ Tertiary Level & 936 & 23 & $11(12.8)$ & 0 & 11 & 11.6 \\
\hline${ }^{\mathrm{d}}$ Professional & 342 & 62 & $21(24.4)$ & $1(3.6)$ & 22 & 54.5 \\
\hline Total & 3256 & 2052 & 86 & 28 & 114 & 21.5 \\
\hline
\end{tabular}

$* M=$ Male, ${ }^{*} F=$ Female, ${ }^{a}$ Primary Level: (University public school, government primary school), ${ }^{b}$ Secondary Level: (University public high school and college, government high and higher secondary School), ${ }^{c}$ Tertiary Level: (Graduate and postgraduate university students), ${ }^{d}$ Professionals (university, college, school teachers, administrative and other employments) 


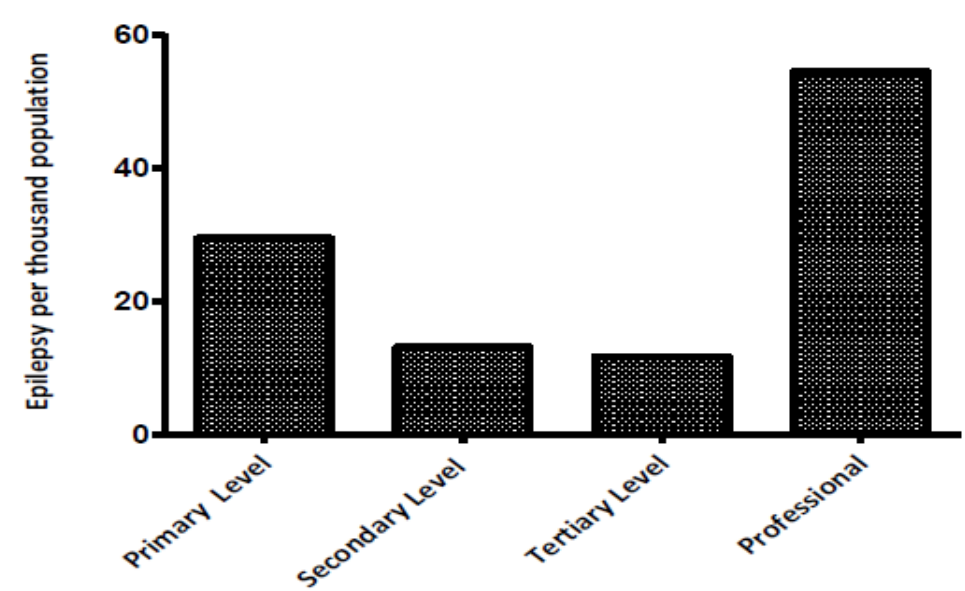

Level of Education

Figure1: Graphical presentation of epilepsy per thousand populations

Similarly Table 2; shows age and sex prevalence numbers $(n)$ and percentages (\%) among positive cases. High prevalence percentages were reported in the age range of 11-20 years among both genders male (61.6) and female

Table2: Age and Sex specific prevalence rates of epilepsy within an educational hub of Sheringal $(n=114)$

\begin{tabular}{|c|c|c|c|}
\hline Age (Years) & Male $n(\%)$ & Female $n(\%)$ & Total $n(\%)$ \\
\hline$\leq 5$ & $\begin{array}{ll}1 & (1.2) \\
\end{array}$ & 0 & $\begin{array}{ll}1 & (0.9) \\
\end{array}$ \\
\hline 6-10 & $\begin{array}{ll}5 & (5.8) \\
\end{array}$ & $\begin{array}{ll}7 & (25.0)\end{array}$ & $12(10.5)$ \\
\hline $11-20$ & 53 (61.6) & $\begin{array}{ll}17 & (60.7)\end{array}$ & $70(61.4)$ \\
\hline $21-30$ & 16 (8.6) & $3 \quad(10.7)$ & $19(16.7)$ \\
\hline $31-40$ & $\begin{array}{ll}5 & (5.8)\end{array}$ & $1 \quad(3.6)$ & $\begin{array}{ll}6 & (5.3)\end{array}$ \\
\hline $41-50$ & $\begin{array}{ll}6 & (7.0) \\
\end{array}$ & 0 & (5.3) \\
\hline $51-60$ & 0 & 0 & 0 \\
\hline$\geq 61$ & 0 & 0 & 0 \\
\hline Total & $86(75.44)$ & $28(24.56)$ & $114(2.14)$ \\
\hline
\end{tabular}

$n=$ number, $\%=$ Percentage

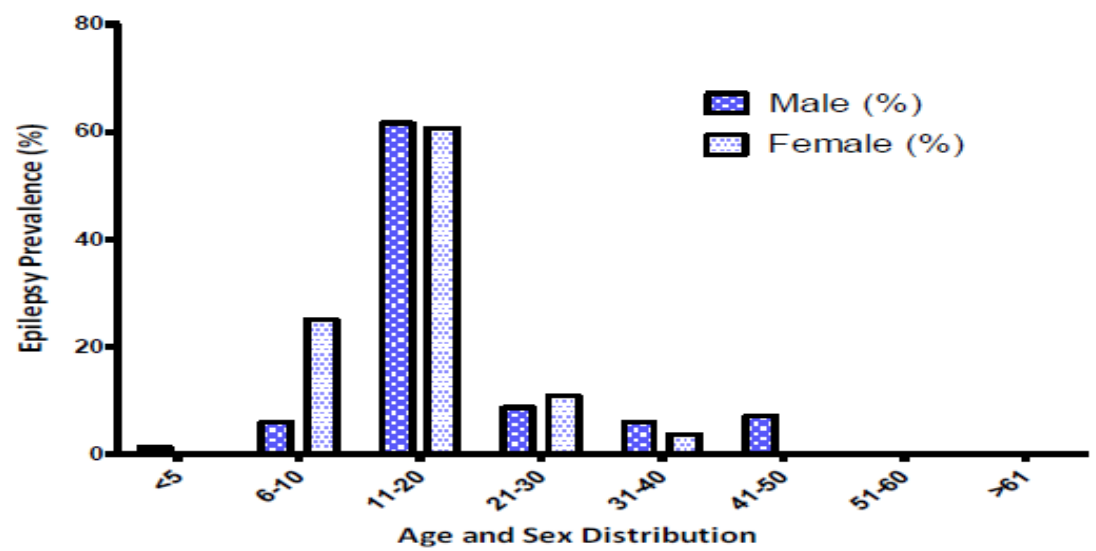

Figure2: Age and Sex wise Prevalence Percentage of Epilepsy

Table 3; shows results for a simple encounter question about awareness regarding epilepsy and their respondents among epileptic patients and in general sampled population. As for this we randomly distributed $n=500$ questioners among the secondary, tertiary and professional level. We get in return $n=393$ (78.7\% response rate) responses. Among these finding, $64.9 \%$ of
(60.7), which constitutes a total of $61.4 \%$. Positive epilepsy among older people was also reported in both genders. Figure 2; shows graphical presentation of age-sex prevalence's. the epileptic patients were unaware about their disease status; $4.4 \%$ of them were have excellent awareness. While in general population the response was poor $(63.1 \%)$. Awareness in excellent level was poor $(9.4 \%)$. Figure 3; graphically shows the awareness amongst epileptic and general populations. 
Awareness and Prevalence of Epilepsy; a Study in Educational Hubs at Sheringal, Khyber Pakhtunkhwa, Pakistan

Table3: Level of awareness in people with Epilepsy $(n=114)$ and in the general sampled population $(n=393)$

\begin{tabular}{|l|l|l|}
\hline $\begin{array}{l}\text { Awareness Respondents regarding } \\
\text { epilepsy }\end{array}$ & $\begin{array}{l}\text { Respondent amongst } \\
\text { Epileptic Patients } \boldsymbol{n}(\boldsymbol{\%})\end{array}$ & $\begin{array}{l}\text { Respondent in Sampled } \\
\text { Population } \boldsymbol{n}(\boldsymbol{\%})\end{array}$ \\
\hline Excellent & $5 \quad(4.4)$ & $37(9.4)$ \\
\hline Adequate & $16(14.0)$ & $45(11.5)$ \\
\hline Average & $19(16.7)$ & $63(16.0)$ \\
\hline Poor & $74(64.9)$ & $248(63.1)$ \\
\hline Total & 114 & 393 \\
\hline
\end{tabular}

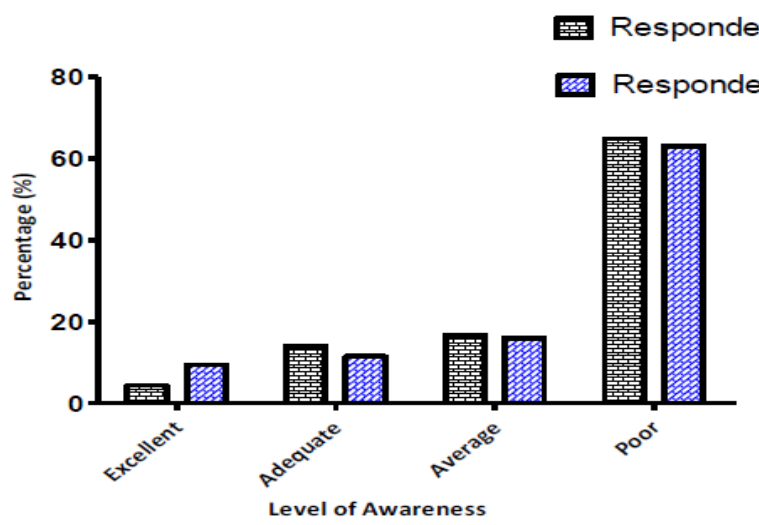

Figure3: Level of awareness percentage in people with Epilepsy $(n=114)$ and in the general Sampled population $(n=393)$

Table 4; shows results for the basic acquired questions about epilepsy awareness from $n=393$ respondents at different level with in the education hub. Question 1-4 gives us responses about the familiarity of epilepsy; mean that how much people are proverbial with epilepsy.

Table4: Basic acquired questions regarding Epilepsy awareness at different level within the education hub of Sheringal $(n=393)$

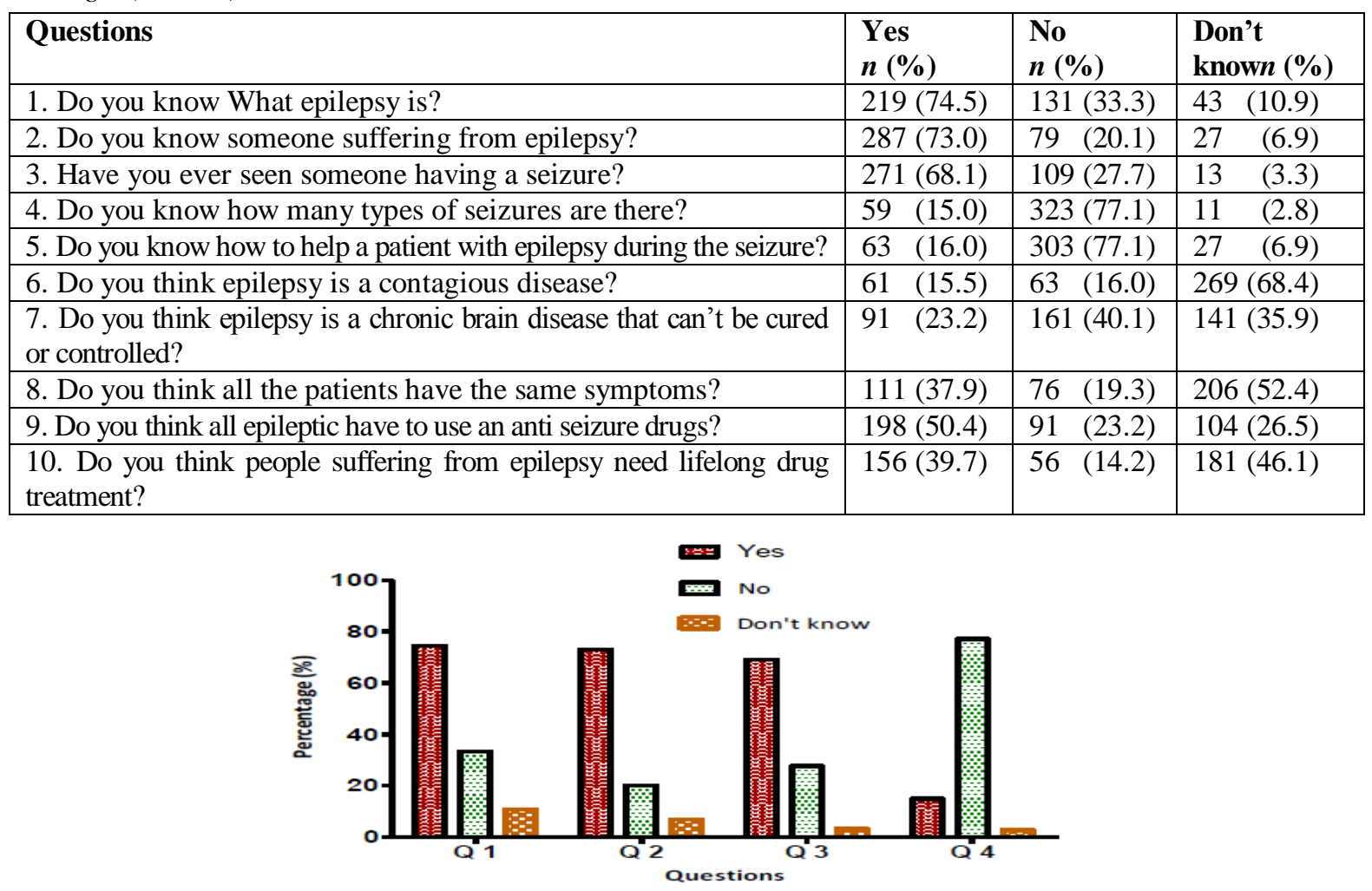

Figure4: Questions regarding familiarity with epilepsy among the sampled population and their percentages. $Q$ 1: Do you know What epilepsy is?, Q 2: Do you know someone suffering from epilepsy?, Q 3: Have you ever seen someone having a seizure?, $Q 4$ : Do you know how many types of seizures are there? 


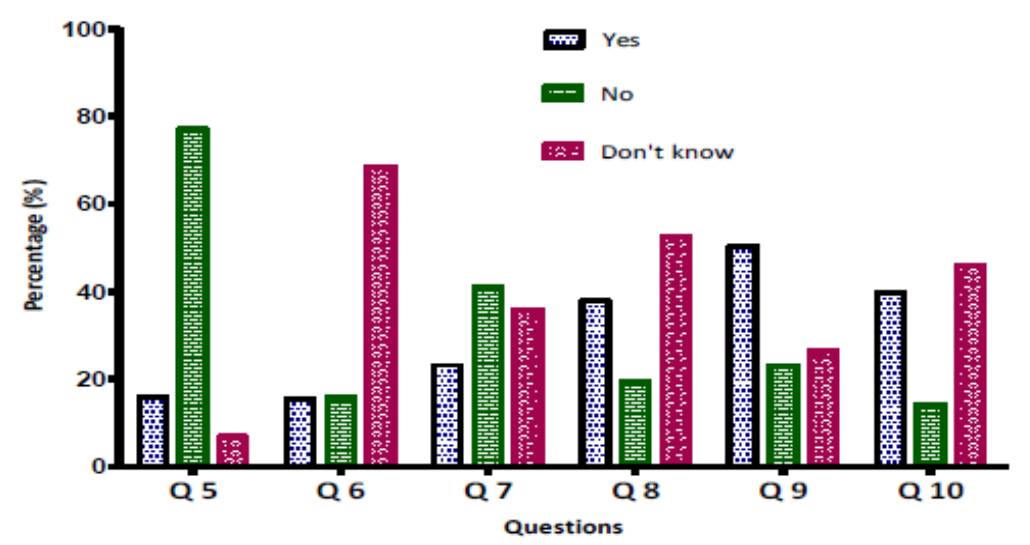

Figure5: Questions regarding understanding of epilepsy among the sampled population and their percentages. $Q$ 5: Do you know how to help a patient with epilepsy during the seizure?, $Q$ 6: Do you think epilepsy is a contagious disease?, $Q$ 7: Do you think epilepsy is a chronic brain disease that can't be cured or controlled?, $Q$ 8: Do you think all the patients have the same symptoms?, $Q$ 9: Do you think all epileptic have to use an anti seizure drugs?, Q 10: Do you think people suffering from epilepsy need lifelong drug treatment?

Table 5; shows results for basic acquired questions about epilepsy from epileptic people. Question 1-9 comprises of those that questions that is related to understanding of epilepsy.
Questions 10-14; were a small attempt to credible social and environmental causative factors. Figure 6; shows graphical presentation of these questions.

Table5: Basic acquired questions regarding Epilepsy from epileptic people within educational hub $(n=114)$

\begin{tabular}{|l|l|l|ll|}
\hline Questions & $\begin{array}{l}\text { Yes } \\
\boldsymbol{n}(\boldsymbol{\%})\end{array}$ & $\begin{array}{l}\text { No } \\
\boldsymbol{n}(\boldsymbol{\%})\end{array}$ & $\begin{array}{l}\text { Don't } \\
\boldsymbol{n}(\boldsymbol{\%})\end{array}$ \\
\hline know \\
\hline 2. Are you suffering from epilepsy? & $108(94.7)$ & $2(1.8)$ & 4 & $(3.5)$ \\
\hline 3. Are you taking Epileptic drugs (tablets)? & $25(21.9)$ & $89(78.1)$ & 0 & $(0.0)$ \\
\hline 4. Do you feel symptoms with Epileptic seizure? & $98(85.1)$ & $7(6.1)$ & 4 & $(3.5)$ \\
\hline 5. Do you visit your doctor or clinic regularly about your Epilepsy? & $29(25.4)$ & $85(74.6)$ & 0 & $(0.0)$ \\
\hline $\begin{array}{l}\text { 6. Have you ever been admitted to hospital to control your } \\
\text { Epileptic seizure? }\end{array}$ & $23(20.2)$ & $91(79.8)$ & 0 & $(0.0)$ \\
\hline 7. Have you been admitted to hospital for treatment? & $23(20.2)$ & $91(79.8)$ & 0 & $(0.0)$ \\
\hline 8. Is any severity with passage of time occurred? & $16(14.0)$ & $98(85.1)$ & 0 & $(0.0)$ \\
\hline 9. Do you have knowledge about epilepsy? & $19(16.7)$ & $91(79.8)$ & 4 & $(3.5)$ \\
\hline 10. Do you use narcotics (drugs)? & $11(9.6)$ & $103(90.4)$ & 0 & $(0.0)$ \\
\hline 11. Cousin marriage occurred among your parents? & $10(8.8)$ & $104(91.2)$ & 0 & $(0.0)$ \\
\hline 12. Are you taking stream water for drinking purposes? & $99(86.8)$ & $15(13.2)$ & 0 & $(0.0)$ \\
\hline 13. Do you have Midwife (Dhaye) in your communities? & $26(22.8)$ & $67(58.8)$ & $21(18.4)$ \\
\hline 14. Do they (Midwifes) are involved in maternity health cares? & 8 & $(7.0)$ & $85(74.6)$ & $21(18.4)$ \\
\hline
\end{tabular}

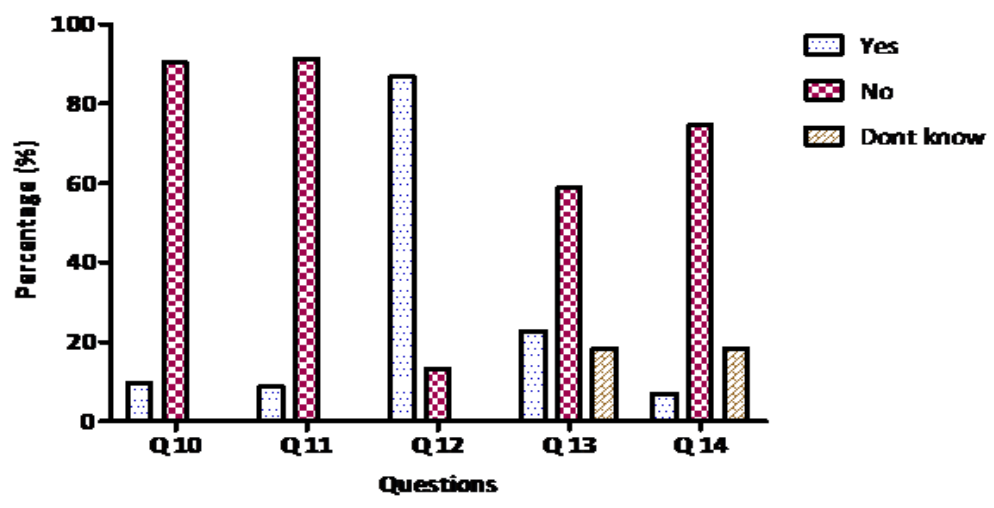

Figure6: Graphical Presentation of Credible Social and Environmental causative Factors of Epilepsy. Q 10: Do you use narcotics (drugs)? Q 11: Cousin Marriage occurred among your parents? Q 12: Are you taking stream water for drinking purposes? Q 13: Do you have Midwife (Dhaye) in your communities? $Q$ 14: Do they (Midwifes) are involved in maternity health cares? 


\section{DISCUSSIONS}

These are the preliminary studies from Sheringal, KP, Pakistan; on prevalence and awareness of epilepsy. In this survey the cumulative epilepsy percentage among both gender within the educational hub were $2.2 \%$; which makes prevalence of 21.5 per thousand of the sampled population; that were higher than the other results reported from Pakistan as well as both from developed and developing countries [23]. It shows that epilepsy and other seizure disorders are common and frequent in this region. Though these findings were having limitations; confined only to the educational hub of the Sheringal region. At primary, secondary, tertiary and professional levels; active epileptic cases in per thousand of the population were 29.4, 13.1, 11.6 and 54.5 respectively. These high prevalence figures may be due to so many factors e.g. cultural, traditions, customs, socioeconomic status, environmental, religious, genetics, illiteracy, hard, hilly and remote area etc; that need further extensive researches at social, behavior, genetics and molecular level. Beside these; it may also be due to population size sampled from selected population. Community based studies will further justify and vindicate these figures. The average prevalence rate in 32 studies from different parts of the world has been estimated at 5.16/1000 [23]. In Pakistan, 11.1 (an average in urban and rural areas)[14], While some studies reported 9.8 [15, 24], 6.7-8 in different regions of Ecuador, 6.54 in Saudi Arab, 5.7-6.8 in USA, 5.6 in Turkey, 5.3 in Nigeria, 4.8 in China, 4.8 among the Parsi community in India and 3.6 in Tunisia $[12,25]$.

There were so many studies that did not show any significant gender difference [26],But most of the surveys show high prevalence percentages in male; which is assumed to reflect the contribution of etiologic factors such as head trauma known to be more frequent in males [12, 27]. Similarly high prevalence percentage in female at primary $(60.7 \%)$ and secondary (35.7); while these percentages were higher at tertiary and professional level in male population; $20.9 \%$ and $12.8 \%$ respectively. It is possible that epilepsy in women was underreported due to various social and cultural factors [28], which need to be explored especially in this male dominant hard-area.

High percentages were reported in the age range of 11-20 years among both genders male and female, which constitutes a total of $61.4 \%$; 21 -
$30(16.8 \%)$ and $5.2 \%$ between the age of $31-50$ years. Previous studies reported that $50 \%$ of the cases of epilepsy begin in childhood or adolescent and its prevalence's are higher in pediatric ages $[21,28]$. Studies also reported positive epilepsy among older people in both genders. There is a lack of data on the epidemiology in all age; especially from remote areas of KPK in Pakistan; even though epilepsy is the most common serious chronic neurological condition in different age groups. The crude prevalence rate of epilepsy, of 9.98/1000 population of all age groups, has been reported in Pakistan and among these, $74.0 \%$ were aged $\leq 18$ years. Whereas these percentages keeps fluctuating from country to country in Asia. The medium lifetime prevalence of epilepsy is estimated at 6/1000 persons in Asia [21, 29]. Child and adulthood epilepsy is increased when risk factors such as febrile seizures, head trauma, central nervous system infections, mental retardation and cerebral palsy are present [28].

Knowing about a disease and their management is very much essential for the patients suffering and for the general population; especially in remote and hard areas. It is very much important for the prevention of inadequate information of future health care providers. Consequently, this may result in improved health support and quality of life of one suffering from various diseases. This study included questions on awareness of epilepsy [9]. Several studies have investigated public awareness and attitudes toward epilepsy in both developed and developing countries [22, 30-33]. The results of these studies are not firmly similar because of the variation in population studied, questionnaires adopted, study design, respondents and methods used. Whereas some researchers have studied the whole population, a majority has sampled the population by different methods, either included or excluded the persons suffering from epilepsy [8]. In our studies, we mostly used closed-ended questions; for the sake of respondents understanding, open-ended question were also used as facilitating the response. Questions were answered either through postal inquiry, telephone inquiry and personal tend to answer differently in face-to-face interviews or than in a selfadministered questionnaire. We explore awareness regarding epilepsy and their respondents among epileptic patients (through face to face interview) and in general sampled population (self administered questioner). Among these $64.9 \%$ of 
the epileptic patients while $63.1 \%$ among general sampled population were unaware about their disease status; that may be due to poor states health and social policies regarding diseases and their managements. There are only two basic health units; one is within the premises of education hub while the other situated within the Sheringal local community. Both have physicians, technicians, lady health workers, nurses and dispensers. But most of the people preferred cities for their primary care; which is at a long distance of about $200 \mathrm{Km}$ from Sheringal. Poor patient counseling, pharmaceutical care and compliances; that are one of the key components of rational health services; subsist, that is the whole country problem. Besides that people trust that epileptic patients are possessed by evil and spirits and for that they referred religious spiritual healings and theo-therapies. Very few people were having excellent awareness; that may be due to the life sciences students (pharmacy, biotechnology, zoology etc). Some of respondents have adequate and average knowledge about the diseases that mostly affect brain. The study explored awareness at different level in a highly literate epileptic and non epileptic population of Sheringal. Studies from developing and developed countries mentioned by Radhakrishnan, K., et al., 2000 [8], have revealed an awareness rate which is totally dissimilar to our current findings from this region of KPK, Pakistan. This high degree of awareness about epilepsy among the people of developing countries may be related to the high literacy rate, health policies, overpopulated conditions and closer interpersonal relationships [8].

Familiarities with epilepsy vary in different countries according to their own social, medical, traditional, behavior and religious aspects and respects. The data shows results for the basic acquired questions (Q-1-4); which revealed that most of the people are familiar $(74.6 \%)$ with the word epilepsy; they have heard about epilepsy. That is because elaborate the Q-1 to a level that can easily understand by the respondent in a local and non-medical language. For example, when we asked a question about whether or not he is aware about epilepsy, "Meerge" (in local language), seizures, and jerks; with troublesome understanding ultimately he replied in "yes"; followed by similar questions. This was the foremost strategy we planned to avoid the obstacles that pinpoint epileptic patients especially at primary and secondary level. The fear of stigmatization makes them hide their present status. Similarly it showed that $33.33 \%$ were not familiar with the word Epilepsy, in addition $10.9 \%$ were completely clueless about this, while $10.9 \%$ answered, didn't know. $70.1 \%$ (average) of the respondents have seen either epileptic patients or seizures. Majority of them were devoid of the knowledge about the types of epilepsy. These finding were comparable up to some extents and limitation with C.G. Fong and Hung (2002) [10] findings.

Understanding a disease is very much imperative in all societies. If people know about causes, first aid management and drug treatment of diseases; they can avoid stigmiazation, false belief, negative attitudes, non-compliance and unawareness that may create problems in the rational therapeutic approaches. Questions 5-10 give us indications that how much people understand epilepsy. Q-5 shows that $77.1 \%$ respondents don't know the initial procedure; how to attend and handle a patient during convulsions. These types of studies have been reported [34], that were somewhat comparable. These difficulties were probably due to poor educative programs in epilepsy especially at primary levels. Therefore, services for educational health must be developed in special accordance to epilepsy In remote areas to overcome its consequences as early as possible [34]. People try to avoid communications and physical contact with the patients $15.0 \%$ of the respondents assumes that it is contagious or infective, whereas majority $(68.4 \%)$ showed complete unawareness; Of about $40.1 \%$ people were deprived of the knowledge that epilepsy is a chronic neurological disorder and it can't be cured. While $35.9 \%$ respondents are unaware of the fact that can be treated and managed. About the symptoms; $37.9 \%$ people think that all epileptic patients have same sign symptoms; 52 . $4 \%$ don't know; $50.4 \%$ people know that epileptic patient can be treated through antiseizure drugs while $26.5 \%$ were unaware. Majority of the respondents were unaware about this fact that epileptic patient will use lifelong anti-seizure drugs. Somewhat similar studies were reported by [9]but the reports were confined to pharmacy students. Antiepileptic agents can successfully manage epilepsy [35] and hence improving quality of life in patients with epilepsy. It has been observed and reported that many patients with epilepsy have 
inadequate seizure control due to poor medication compliance [36].

It is very important for a patient to be aware about their disease status and their management. Because it can avoid non compliances regarding treatment approaches. Similarly Q 1-9 reflects understanding attitude of the epileptic patients toward their disease and treatment. Majority of them were aware (94.7\%) about their disease status; $78.1 \%$ respond that they have no disease other than epilepsy, $85.1 \%$ were adhere to their medication which shows remarkable compliances. $89.47 \%$ of the epileptic respondents showed that they can feel symptoms before and after the convulsions. Poor responses were seen among the respondents about their regular clinical visits; $74.56 \%$ of epileptic people mentioned that when they got severity or complications; they would visit a physician. $79.8 \%$ respondent's shows that they did not admit in a hospital for seizure control neither for proper treatment; $85.96 \%$ of them shows no severity in the disease status with the passage of time. Referring to Q 9; 79.8\% of the epileptic respondents shows that they have no extensive knowledge about epilepsy. They know very little about this case as a neurological disorder.

Due to unavailability of magnetic resonance imaging (MRIs) and computer tomography (CT) scan at door steps in Sheringal, many of symptomatic epilepsies might have been missed or probably classified as idiopathic. Previous studies reported that $65-70 \%$ of epilepsies having no clear etiology. While among these studies 57\% reported in Arab [25] were due to pre or perinatal fixed encephalopathy, which is higher than the $4.8 \%$ reported from Rochester, USA [37] or even the $10 \%$ reported from Tunisia [38]. Surprisingly, prenatal fixed encephalopathy was not reported as a cause of epilepsy in either China or Pakistan [23].In Pakistan, it may be due to poor research approaches. Pediatric intracranial infection was the second most common etiology in so many cases with a frequency of $4 \%$ similar to the $35 \%$ reported from other places except Pakistan where it constituted almost $10 \%$ of the cases [23].Head injury, CNS infections, birth trauma, cerebrovascular disease, cerebral palsies, strokes, cerebral tumors, consanguineous marriages were the most causative factors reported in developed as well as in developing countries [23, 37, 39, 40]. In the current studies; an attempts were made on credible social and environmental causative factors (mentioned in Q
10-14); which need further exploration. No etiology (idiopathic, cryptogenic or symptomatic) on molecular or gene level was identified; some counter questions regarding drug abuse, cousin marriages, drinking water sources and local midwifes involve in handling labor inductions were asked. Among these $86.8 \%$ respondents consistently use stream water; which mostly comes from rocks and mountains containing minerals and salts in sufficient amount. Only $9.6 \%$ of the respondents using narcotics drugs; that may be due to the fact that they hide the reality; as it is consider as a nuisance and curse in this society. The percentages of cousin marriages were also very low. Beside that midwifes which are mostly untrained are actively involved in maternity health and child births. Non-technicality and mishandling during births may lead to minor to major head injuries which may appear later on in the form of fits and seizures.

\section{Conclusions}

It is concluded that prevalence of epilepsy is higher within educational hub in Sheringal area which is 21.5 per thousand of the population. The most frequent age limit is 11-20 among both genders. It was observed that level of awareness were very poor among epileptic as well as in general population of the educational hub. Most of the educated communities including epileptic patients were unfamiliar with epilepsy and its management. Credible social and environmental causative factors that may cause or may enhance epilepsy were also determined. Majority of population use stream water for drinking purposes; which mostly contains heavy metals and salts that may take part in neurological disorders. Untrained midwifes that mostly handled maternity health in this area; may also contribute in seizures.

\section{STUDIES LIMITATIONS}

Existing knowledge on the awareness and prevalence studies of epilepsy at primary, secondary, tertiary and professional level has been derived mainly from studies conducted or reported. However, difference in socio-cultural, traditional, behavior, ethnic composition, disease prevalence and awareness responses may not be entirely applicable to the other hard and remote areas of Pakistan. Local data are important in order to assess the magnitude of the problem and to target resources to patients and projects most in need. This information would certainly be of prime importance as part of the 
efforts to fill what has been called the "treatment gap" in epilepsy, especially among distant population of the country. For this WHO has recommended a strategy integrating epilepsy services at primary level; which need proper regulation and implementation.

\section{RECOMMENDATIONS}

From these finding, it is recommended that in $\mathrm{KP}$, epilepsy should be properly monitored for prevalence and awareness responses at districts and union council and at all level of educations and professions as well, as they are consistently interact and may inversely affect the sufferers by self as well as make miserable the life quality of general population. People should be properly educated and trained for the first aid management of epilepsy. The community should avoid discriminations, stigmatization, false belief, perception regarding epilepsy and their victims.

\section{ACKNOWLEDGEMENT}

The author sincerely thanks to the Department of Pharmacy and Department of Zoology, Shaheed Benazir Bhutto University, Sheringal, Pakistan for supporting this project.

\section{REFERENCES}

[1] Malik MA, Akram RM, Tarar MA, Sultan A: Childhood epilepsy. J Coll Physicians Surg Pak 2011, 21:74-78.

[2] Zhang Y, Yu N, Su L, Di Q: A prospective cohort study of prognosis for newly diagnosed epilepsy in east China. BMC neurology 2013, 13(1):116.

[3] Patil S, Biassoni L, Borgwardt L: Nuclear medicine in pediatric neurology and neurosurgery: epilepsy and brain tumors. In: Seminars in nuclear medicine: 2007: Elsevier; 2007: 357-381.

[4] McGuire S: Removing Oneself from the Shadows: A Heuristic Inquiry to Understand the Lived Experience of Epilepsy in Young Adult Women and their Epilepsy Disclosure. 2015.

[5] Löscher W, Schmidt D: New horizons in the development of antiepileptic drugs: Innovative strategies. Epilepsy research 2006, 69(3):183272.

[6] Ngugi AK, Bottomley C, Kleinschmidt I, Sander JW, Newton CR: Estimation of the burden of active and life-time epilepsy: A meta-analytic approach. Epilepsia 2010, 51(5):883-890.

[7] Keikelame MJ, Swartz L: "The others look at you as if you are a grave": a qualitative study of subjective experiences of patients with epilepsy regarding their treatment and care in Cape Town, South Africa. BMC international health and human rights 2016, 16(1):9.

[8] Radhakrishnan K, Pandian J, Santhoshkumar T, Thomas S, Deetha T, Sarma P, Jayachandran D, Mohamed E: Prevalence, knowledge, attitude, and practice of epilepsy in Kerala, South India. Epilepsia 2000, 41(8):1027-1035.

[9] Anjum F, Ghayas S, Ali T, Jahan N, Qadeer H, Arshad A: Awareness of epilepsy in pharmacy students in different universities of Karachi, Pakistan. African Journal of Pharmacy and Pharmacology 2014, 8(10):278-283.

[10] Fong CyG, Hung A: Public awareness, attitude, and understanding of epilepsy in Hong Kong Special Administrative Region, China. Epilepsia 2002, 43(3):311-316.

[11] Brenman NF, Luitel NP, Mall S, Jordans MJ: Demand and access to mental health services: a qualitative formative study in Nepal. BMC international health and human rights 2014, 14(1):22.

[12] Aydin A, Ergor A, Ergor G, Dirik E: The prevalence of epilepsy amongst school children in Izmir, Turkey. Seizure 2002, 11(6):392-396.

[13] Razi N: Theological Extremism and its Effects: Pakistan Perspective. Journal of Social Science for Policy Implications 2014, 2(4):59-72.

[14] Khatri I, Iannaccone S, Ilyas M, Abdullah M, Saleem S: Epidemiology of epilepsy in Pakistan: review of literature. Journal of the Pakistan Medical Association 2004(53):594597.

[15] Aziz H, Ali S, Frances P, Khan M, Hasan K: Epilepsy in Pakistan: A Population-Based Epidemiologic Study. Epilepsia 1994, 35(5):950-958.

[16] Khan MS, Akhter M: Epilepsy in rural community of Pakistan: a description of one hundred patients. Journal-College of Physicians and Surgeons of Pakistan 2002, 12:728-730.

[17] Afzal M, Shahid M: Children presenting with seizures-A hospital based study. J Coll Physicians Surg Pak 1999, 9(3):132-135.

[18] Aziz H, Hasan M, Hasan KZ: Prevalence of epilepsy in children (a population survey report). Prevalence 1991.

[19] Hazrat A, Nisar M, Shah J, Ahmad S: Ethnobotanical study of some elite plants belonging to Dir, Kohistan valley, Khyber Pukhtunkhwa, Pakistan. Pak J Bot 2011, 43(2):787-795.

[20] Perveen F, Khan N, Saeedi N, Damavandian MR: Exploring of the first recorded spider (Arachenida: Aranae) species of Sheringal, Khyber Pakhtunkhwa, Pakistan. Arthropods 2015, 4(3):69. 
[21] Muhammad Akbar Malik RMA, Muhammad Arif Tarar and Ashraf Sultan: Childhood Epilepsy. Journal of the College of Physicians and Surgeons Pakistan 2011, 21(2):74-78.

[22] Aziz H, Akhtar SW, Hasan KZ: Epilepsy in Pakistan: Stigma and Psychosocial Problems. A Population-Based Epidemiologic Study. Epilepsia 1997, 38(10):1069-1073.

[23] Al Rajeh S, Awada A, Bademosi O, Ogunniyi A: The prevalence of epilepsy and other seizure disorders in an Arab population: a communitybased study. Seizure 2001, 10(6):410-414.

[24] Mac TL, Tran D-S, Quet F, Odermatt P, Preux P-M, Tan CT: Epidemiology, aetiology, and clinical management of epilepsy in Asia: a systematic review. The Lancet Neurology 2007, 6(6):533-543.

[25] S. AL Rajeh AA, O. Bademosi and and A. Ogunniyi: The prevalence of epilepsy and other seizure disorders in an Arab population: a community-based study. Seizure 2001, 10:410414.

[26] Gaitatzis A, Carroll K, Majeed A, Sander JW: The epidemiology of the comorbidity of epilepsy in the general population. Epilepsia 2004, 45(12):1613-1622.

[27] Annegers JF, Grabow JD, Groover RV, Laws ER, Elveback LR, Kurland LT: Seizures after head trauma A population study. Neurology 1980, 30(7):683-683.

[28] Adem Aydin AE, Gul Ergor and Eray Dirik: The prevalence of epilepsy amongst school children inIzmir, Turkey. Seizure 2002, 11:392-396.

[29] Wong V: Study of seizure and epilepsy in Chinese children in Hong Kong: period prevalence and patterns. Journal of child neurology 2004, 19(1):19-25.

[30] Iivanainen M, Uutela A, Vilkkumaa I: Public awareness and attitudes toward epilepsy in Finland. Epilepsia 1980, 21(4):413-423.
[31] Baumann RJ, Wilson JF, Wiese HJ: Kentuckians' attitudes toward children with epilepsy. Epilepsia 1995, 36(10):1003-1008.

[32] Jensen R, Dam M: Public attitudes toward epilepsy in Denmark. Epilepsia 1992, 33(3):459-463.

[33] Chung MY, Chang Yc, Lai YHC, Lai CW: Survey of public awareness, understanding, and attitudes toward epilepsy in Taiwan. Epilepsia 1995, 36(5):488-493.

[34] Dantas FG, Cariri GA, Cariri GA, Ribeiro Filho ARV: Knowledge and attitudes toward epilepsy among primary, secondary and tertiary level teachers. Arquivos de neuro-psiquiatria 2001, 59(3B):712-716.

[35] Beyenburg S, Mitchell AJ, Schmidt D, Elger $\mathrm{CE}$, Reuber M: Anxiety in patients with epilepsy: systematic review and suggestions for clinical management. Epilepsy \& Behavior 2005, 7(2):161-171.

[36] Jones EJ, MacKinnon NJ, Tsuyuki RT: Pharmaceutical care in community pharmacies: practice and research in Canada. Annals of Pharmacotherapy 2005, 39(9):1527-1533.

[37] Hauser WA, Kurland LT: The epidemiology of epilepsy in Rochester, Minnesota, 1935 through 1967. Epilepsia 1975, 16(1):1-66.

[38] Attia-Romdhane N, Mrabet A, Hamida MB: Prevalence of epilepsy in Kelibia, Tunisia. Epilepsia 1993, 34(6):1028-1032.

[39] Placencia M, Shorvon S, Paredes V, Bimos C, Sander J, Suarez J, Cascante S: Epileptic seizures in an Andean region of Ecuador. Brain 1992, 115:771-782.

[40] Haerer AF, Anderson DW, Schoenberg BS: Prevalence and clinical features of epilepsy in a biracial United States population. Epilepsia 1986, 27(1):66-75.

Citation: Nazish Akhter, Zul Kamal, Faiz Ur Rahman, Pinky Sultana, Zahra Dhurrani. Awareness and Prevalence of Epilepsy; a Study in Educational Hubs at Sheringal, Khyber Pakhtunkhwa, Pakistan. ARC Journal of Neuroscience. 2018; 3(1):9-20. doi:dx.doi.org/10.20431/2456-057X.0301003.

Copyright: (c) 2018 Authors. This is an open-access article distributed under the terms of the Creative Commons Attribution License, which permits unrestricted use, distribution, and reproduction in any medium, provided the original author and source are credited. 